\title{
A Health Impairment Process of Sickness Presenteeism in Norwegian Physicians: The Mediating Role of Exhaustion
}

\author{
Sylvi Thun'1, Lise T. Løvseth ${ }^{2}$ \\ ${ }^{1}$ Department of Psychology, Norwegian University of Science and Technology (NTNU), Trondheim, Norway \\ ${ }^{2}$ Department of Research and Development, Division of Psychiatry, St Olav's Hospital, Trondheim, Norway \\ Email: lise.lovseth@ntnu.no
}

Received 4 May 2016; accepted 12 June 2016; published 15 June 2016

Copyright (C) 2016 by authors and Scientific Research Publishing Inc.

This work is licensed under the Creative Commons Attribution International License (CC BY).

http://creativecommons.org/licenses/by/4.0/

c) (7) Open Access

\begin{abstract}
Although work factors have been associated with both presenteeism and exhaustion among hospital physicians, we lack knowledge on the dynamic relationship between demands in the work context and presenteeism and how this can be mediated by symptoms of exhaustion when controlling for job resources. The objective of this study is to examine a health impairment process of presenteeism among university hospital physicians. A cross-sectional survey of 545 university hospital physicians in Norway was conducted. Variables included in the model were presenteeism, exhaustion, work-family conflict, role conflict, social support and control over work pace. Findings from structural equation modeling indicated that exhaustion mediates the relationship between job demands and presenteeism. Job resources had no direct effect on presenteeism in the hypothesized model. The variables in the study explained $17 \%$ of the variance in presenteeism. The study is one of the first to demonstrate that the relationship between job demands and presenteeism is mediated by exhaustion when controlling for job resources. The results highlight the importance of considering the link between health symptoms and job demands to reduce the negative effects of presenteeism.
\end{abstract}

\section{Keywords}

Sickness Presenteeism, Exhaustion, Job Demands, Job Resources, JD-R Theory

\section{Introduction}

A considerable number of studies show that hospital physicians worldwide both manifest high levels of exhaus- 
tion as a symptom of burnout [1]-[4] and attend work despite their own ill-health, a phenomenon termed sickness presenteeism [5]-[8]. Though exhaustion and presenteeism have been associated with similar work and personal factors, only a few studies have indicated a relationship between these health behaviors [8]-[10]. We also lack studies that examine the dynamic relationship between these factors and their relative contribution to a health impairment process manifested by exhaustion and presenteeism. This knowledge is vital to initiate interventions that can reduce both exhaustion and unwanted presenteeism among physicians. An important step is to examine how exhaustion mediates the relationship between factors in the work context and presenteeism within an established model of occupational stress such as the Job-Demand-Resources (JD-R) model.

A recent meta-analysis on the correlates of presenteeism concluded that significant contributors are job demands and perceived stress, negative relational experiences, positive attitudes, and lack of personal and job resources [11]. This is concordant with studies that show a high rate of sickness presence and low sickness absence among professionals with high job demands and those who report that their skills and tasks are difficult to allocate to others [12], such as physicians in academic medicine [5] [6] [13]. Their high demands at work combined with family responsibilities can compromise sufficient self-care, restitution, and rest [14] which in turn can contribute to exhaustion and presenteeism. Work tasks in the healthcare service may also stimulate presenteeism because of high work engagement or professional obligations [11]. To understand better the dynamic relationship between work characteristics, exhaustion, and presenteeism it is vital to examine these associations in an occupation that manifests high prevalence of presenteeism such as that of hospital physicians [5] [8].

The JD-R model is a theoretical model of occupational stress that conceptualizes the relationship between employee well-being and job performance. The theory is based on the assumption that all working environments constitute job demands and job resources [15] [16]. Job resources are defined as the physical, social, and organizational features of work that can reduce job demands and are functional in achieving work goals [17]. In contrast, job demands refer to psychological, social, physical, or organizational features of the job that require sustained personal effort and are related to some psychological and/or physiological costs [18]. These include a variety of distinct variables that constitute role demands (e.g., role conflict), time demands (e.g., long hours, shift work) and relational demands (e.g., work-family conflict) [11]. The JD-R theory states that the dynamic relationship between job demands and resources triggers either a health impairment process or a motivational process. Accordingly, the current study emphasizes that job demands are the most important predictors of occupational strain such as exhaustion which in turn predict job performance whereas resources are the most important predictor of work engagement [16] [19]. In contrast to studies that have examined the direct relationship between work factors and presenteeism, the current study suggests that job demands can have an effect on well-being and indirectly influence performance. Considering the health impairment process, we examine if presenteeism as a sign of strain is directly ameliorated by job demands or indirectly through exhaustion as a mediator of presenteeism.

As emotional exhaustion may develop as a consequence of demanding cognitive, affective, and physical strain [20] it can mediate the health impairment process manifested by presenteeism among physicians. Although studies have confirmed a relationship between presenteeism and exhaustion [8] [9], research on the specific link between these two behaviors is inconclusive. One study has suggested that emotional exhaustion is an important target when the aim is to reduce presenteeism [21]. Others suggest a reciprocal relationship between presenteeism and exhaustion because exhausted employees most likely mobilize "compensation strategies" while they attend work when ill [9]. The current study examines the relative influence of different work demands on physicians' exhaustion which in turn can contribute to presenteeism.

Attending work while ill can be regarded as controversial as it can pose high health risks to the person and the patients. However, certain job demands pose high attendance pressure that contributes to presenteeism among physicians [7]. An important job demand that influences psychosocial work climate and generates job-related strain is role conflict [22]. Role conflict is the result of a lack of congruent expectations and demands from other people in the workplace and increases exhaustion [23].

Work-family conflicts are a relational demand that occurs when engaging in one role makes it difficult to engage in another [24]-[26]. Work-family conflict and presenteeism can activate each other [11]. Three types of work-family conflict (time-based, strain-based, and behavior-based) have been identified in the literature. This current study focuses on strain-based conflict and suggests that the strain experienced in one role intrudes into and interferes with participation in another [27] [28]. The interplay between work and family is associated with a range of both positive and negative outcomes and health symptoms including emotional exhaustion [24] [29]. 
A work-family conflict can contribute to presenteeism when work demands force work attendance on behalf of staying home to care a sick child or workers' personal need for restitution, leisure, and rest [30].

In contrast to job demands, job resources such as control over work pace are relevant factors to control for in the health impairment process of presenteeism. Control over work pace refers to the subject's perceived control of time and pace in his or her work [31]. Employees who manifest high presenteeism often work under conditions characterized by time pressure. Despite their poor health they still make a considerable effort to carry out their work duties [32]. It is important to have control over work pace [33] and to get adequate rest to recover and recharge psychologically and physically after demanding efforts at work [34] [35]. In a very demanding job, the decision to be absent or present will vary with work pace [36].

Another important resource in research on presenteeism is social support. Social support refers to perceptions that one has access to helpful relationships of varying quality or strength [37]. Presenteeism is associated with supervisor support and subjective health [38]. Support from colleagues is important for well-being and buffers the negative effects of work stress [39]. It is important to investigate the relative importance of job resources in relation to presenteeism to increase knowledge on how employees respond to the strains of being sickness present [40]. Though job control and social support are regarded as the most important job resources to counterweigh job demands in that workers who experience "being in control" and have a supportive workplace will be less likely to feel pressure to attend when ill [11]. Studies have examined the relative influence of job control and social support on presenteeism [38] [41]-[44].

The objective of this study is to examine the dynamic relationship between different job demands and presenteeism mediated by exhaustion by simultaneously controlling job resources such as control over work pace and social support. This contributes to presenteeism literature by investigating the mediating effect of the employee's health symptoms in the relationship between different job demands and presenteeism, and we control for the two most salient job resources when investigating the health impairment process. According to the JD-R model and the above-mentioned empirical work, the hypotheses of this study are (illustrated in Figure 1):

Hypothesis 1. Exhaustion is positively related to sickness presenteeism.

Hypothesis 2a. Role conflict is positively related to exhaustion and sickness presenteeism.

Hypothesis $2 \mathrm{~b}$. Work-family conflict is positively related to exhaustion and sickness presenteeism.

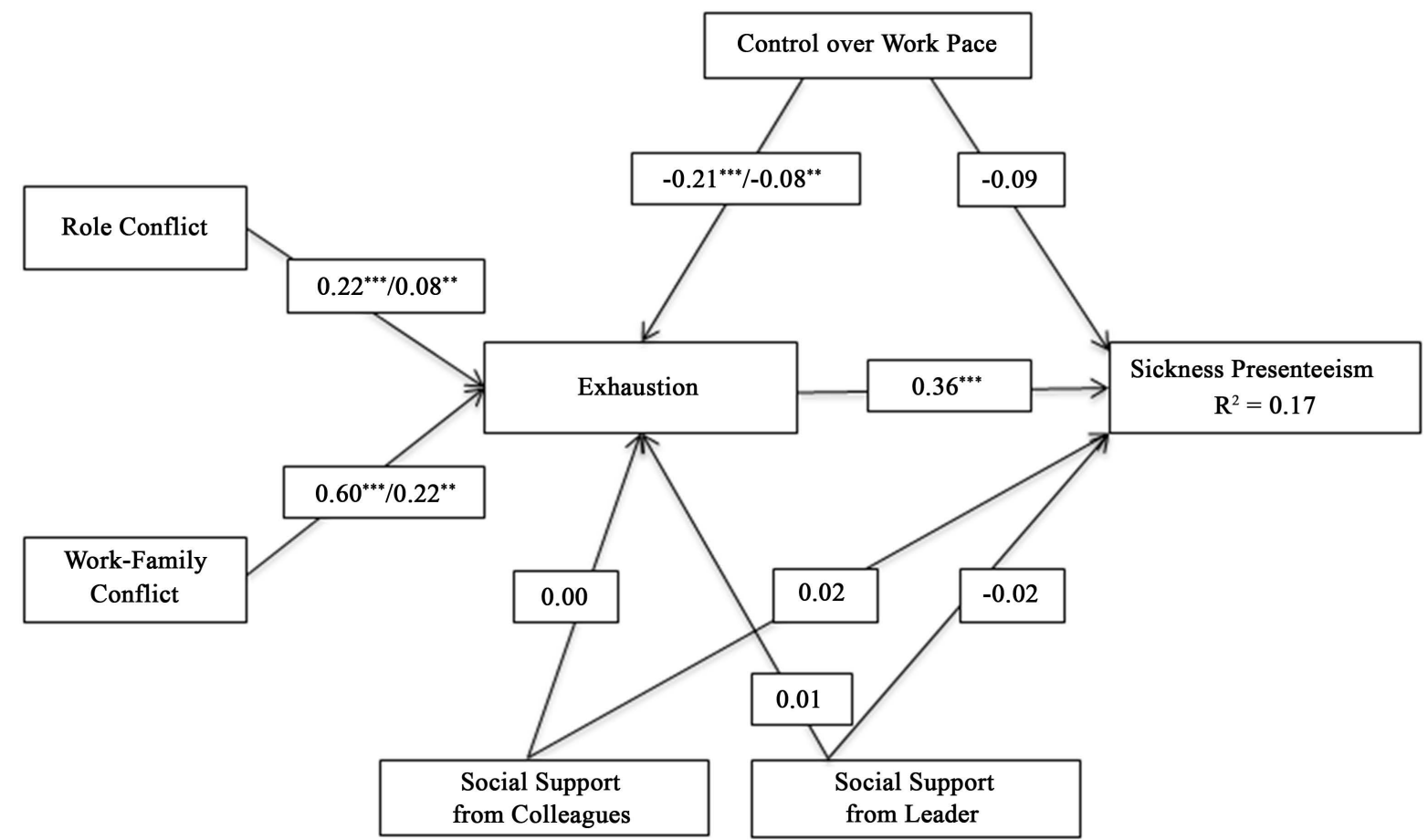

Figure 1. The hypothesized model with direct effects (standardized estimates, $\beta$ in bold) and indirect effects $(\beta)$ for the structural model. ${ }^{* *} p<0.01,{ }^{* * * *} p<0.001$. Fit Indices: $\chi^{2}=231.23, d f=116, p<0.001, \chi^{2} / d=1.99$, GFI $=0.956$, CFI $=$ $0.964, \mathrm{SRMR}=0.043, \mathrm{TLI}=0.953, \mathrm{RMSEA}=0.043, \mathrm{PCLOSE}=0.931$. 
Hypothesis 3a. Exhaustion positively mediated the positive relationship between work-family conflict and sickness presenteeism when controlling for control over work pace and social support.

Hypothesis 3b. Exhaustion positively mediated the positive relationship between role conflict and sickness presenteeism when controlling for control over work pace and social support.

Hypothesis 4. Control over work pace and social support is negatively related to sickness presenteeism.

\section{Method}

\subsection{Participants and Procedure}

This study included data from all participants in a study concerning work-related health, organizational culture, and working conditions among physicians in a Norwegian university hospital conducted from February to May 2012. The participants received a letter containing a personal link to a web-based questionnaire and were asked to provide their responses anonymously. The survey was conducted in English. The inclusions criteria were employment as full-time or part-time physicians actively working at the time of data collection. The project was approved by the administration of the hospital, the union representatives of the physicians at the hospital, and the Regional Ethics Board. In addition to a short oral presentation given in organizational forums, all participants received a letter with a description of the study. All physicians voluntarily participated and completed the informed consent form that was required for participation in the study. The total response rate was $71.8 \%(N=$ $545 / 759)$. Of these responses, $45 \%(n=245)$ were female physicians. A response analysis showed that the sample was representative according to age, gender, and position.

\subsection{Measures}

The questionnaire contained 123 items concerning education, work-related health, organizational culture, and working conditions. The study was based on a selection of variables relevant to the current foci and included presenteeism, exhaustion, role conflict, work-family conflict, control over work pace, social support from colleagues, and social support from supervisors.

\subsubsection{Sickness Presenteeism}

The item "Have you gone to work with an illness in a situation where you would have recommended a patient to stay home? How often has this happened during the last 12 months?” measured sickness presenteeism [6]. The response was rated "none” (1), “once” (2), “2-4 times” (3) and "more than five times” (4).

\subsubsection{Exhaustion}

Exhaustion was measured by a miniature version of the Oldenburg Burnout Inventory [20]. Exhaustion $(\alpha=0.73)$ was measured by five items, and the response scale ranged from $1=$ "totally agree" to 4 = "totally disagree". "After my work, I now need more time to relax than in the past to become fit again" was one item measuring exhaustion. The index included both positively and negatively worded items. The positive and negative items were presented in random order, and the negatively worded items were reversed.

\subsubsection{Role Conflict}

The three items measuring role conflict were derived from the General Nordic Questionnaire for Psychological and Social Factors at Work (QPS Nordic) [45]. The role conflict questions consisted of items about conflicts between demands and resources, conflicting requests, and conflicts between the subject's expectations and external demands [31]. For example, "Do you receive incompatible requests from two or more people?" was measured from 1 = "very seldom or never" to $5=$ "very often or always". The alpha of this scale $(\alpha=0.68)$ corresponded to the validation data on QPS Nordic [46].

\subsubsection{Work-Family Conflict}

Three items such as "When I get home from work I am often too frazzled to participate in family activities/responsibilities" measured work-family conflict [27]. The participants were asked to provide their responses from $1=$ "totally agree" to $4=$ "totally disagree". The items were reversed for the current study purpose. The alpha of this scale $(\alpha=0.84)$ corresponded to a validation study [27]. 


\subsubsection{Control over Work Pace}

The items for the variable "control over work pace" were derived from QPS Nordic [45]. Control over work pace consisted of four items $(\alpha=0.83)$, and the response ranged from "very seldom or never" (1) to "very often or always" (5). The items are about setting work pace, deciding the length and time of breaks, and setting working hours (flexitime) [31]. The alpha of the scale corresponded to the validation data on QPS Nordic [46].

\subsubsection{Social Support}

Social support was measured by the item "How much can people as listed below be relied upon for support when things get tough at work?” [47] [48]. The item was rated with references to the immediate supervisor and the physicians' colleagues (in their work unit), respectively. Responses were on a five-point scale ranging from "not at all" (1) to "very much" (5). A high score for each item of support indicated high levels of support.

\subsection{Analysis}

A confirmatory factor analysis (CFA) using IBM SPSS AMOS version 22 evaluated the outcome data. We performed structural equation modeling (SEM) to test our hypothesized model (Figure 1) based on criteria including: 1) root-mean-square error of approximation (RMSEA) of 0.06 or less indicating good fit; 2) a comparative fit index (CFI) equal to or greater than 0.95 ; and 3) standardized root mean square residual (SRMR) of 0.08 or less [49].

Missing value analysis was conducted with the maximum likelihood (ML) estimation in IBM SPSS Statistics version 22. We investigated modification indices of the measurement model and co-varied some of the error terms on a theoretical basis. A bootstrapping procedure with bias-corrected intervals was conducted to test the indirect effects. This used 1000 bootstraps and a 95\% confidence interval. The assumptions for performing SEM in AMOS were satisfactory. A curve estimation for all the relationships in the model showed that they were sufficiently linear. The assumption of no multicollinearity was confirmed.

\section{Results}

\subsection{Descriptive Statistics}

Table 1 shows details of the constructs and associated items. The model fits for the confirmatory factor analyses (measurement model) are reported as a note in Table 1. Physicians scored a mean of 3.09 on the question "Have you gone to work with an illness in a situation where you would have recommended a patient to stay home?". Information on the descriptive statistics, correlation, and squared correlations $\left(R^{2}\right)$ between the variables is presented in Table 2.

\subsection{The Measurement Model}

The measurement model (Table 1 ) demonstrated a good fit to the data: $\chi^{2}(114)=231.16, p<0.001$, a goodness-of-fit index (GFI) of 0.956, a CFI of 0.963, a Tucker-Lewis Index (TLI) of 0.951, an SRMR of 0.043, and an RMSEA of 0.043 [49] [50]. As shown in Table 1, the Cronbach's alpha and composite reliability coefficients (CR) of the multiple-item measures displayed good internal consistency. Further support for convergent validity as well as discriminant validity was indicated by composite reliability coefficients greater than the recommended 0.7 and average variance extracted (AVE) estimates meeting the critical value of 0.5 [50]. For one measure, the alpha was a little below the commonly accepted threshold of 0.70 . However, this is considered acceptable for measures that have a small number of items [51]. Two variables had AVE values below the critical value of 0.5 , indicating some validity concerns.

\subsection{Results of the Testing of Hypotheses}

Hypothesis 1 that exhaustion was positively related to presenteeism was confirmed ( $\beta=0.36, p<0.001)$. Pearson correlational analysis confirmed Hypothesis 2, indicating a positive relationship between job demands and exhaustion, and job demands and presenteeism. Of the job demands, work-family conflict demonstrated strongest relationship with both presenteeism $(r=0.28, p<0.01)$ and exhaustion $(r=0.55, p<0.01)$ (see Table 2).

The results of the SEM analysis indicated a mediation effect from work-family conflict through exhaustion $(\beta$ $=0.22, p<0.01$ ) on presenteeism (see Figure 1 ). The results showed that an increase in work-family conflict by 
Table 1. Measurement model. Result of confirmatory factor analysis for all study measures.

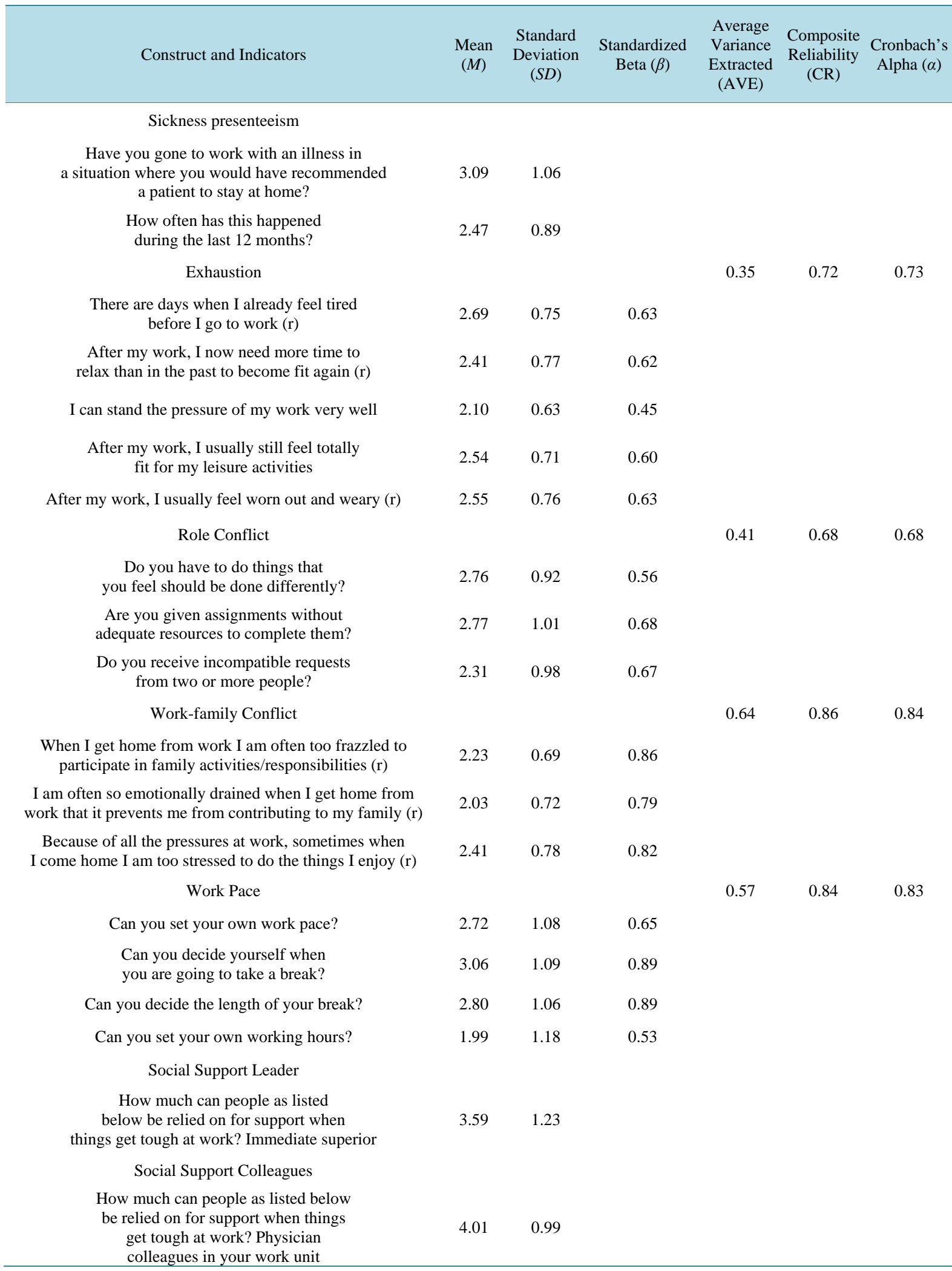

Note: Fit Indices: $\chi^{2}=231.16, d f=114, p<0.001, \chi^{2} / d f=2.028$, GFI $=0.956$, CFI $=0.963$, SRMR $=0.043$, TLI $=0.951$, RMSEA = 0.043, PCLOSE $=0.908$. 
Table 2. Means (M), Standard Deviations (SD), and correlations (Pearson's r) for the sample ( $\mathrm{N}=545)$.

\begin{tabular}{|c|c|c|c|c|c|c|c|c|c|}
\hline & $\begin{array}{l}\text { Mean } \\
(\mathrm{M})\end{array}$ & $\begin{array}{c}\text { Standard } \\
\text { Deviation (SD) }\end{array}$ & 1 & 2 & 3 & 4 & 5 & 6 & 7 \\
\hline 1. Sickness Presenteeism & 2.47 & 0.89 & 0.17 & & & & & & \\
\hline 2. Exhaustion & 2.21 & 0.68 & $0.30^{* *}$ & 0.62 & & & & & \\
\hline 3. Role Conflict & 2.61 & 0.76 & $0.17^{* *}$ & $0.30^{* *}$ & - & & & & \\
\hline 4. Work-Family Conflict & 2.22 & 0.63 & $0.28^{* *}$ & $0.55^{* *}$ & $0.32^{* *}$ & - & & & \\
\hline 5. Work Pace & 2.46 & 1.05 & $-0.25^{* *}$ & $-0.28^{* *}$ & $-0.19^{* *}$ & $-0.17^{* *}$ & - & & \\
\hline 6. Social Support Leader & 3.59 & 1.23 & $-0.14^{* *}$ & $-0.23^{* *}$ & $-0.24^{* *}$ & $-0.29^{* *}$ & $0.22^{* *}$ & - & \\
\hline 7. Social Support Colleagues & 4.01 & 0.99 & $-0.12^{* *}$ & $-0.24^{* *}$ & $-0.19^{* *}$ & $-0.32^{* *}$ & $0.19^{* *}$ & $0.48^{* *}$ & - \\
\hline
\end{tabular}

Note: ${ }^{* *} p<0.01$. $\mathrm{R}^{2}$ of dependent variables in bold.

one $S D$ increased presenteeism by $0.22 S D$ mediated by exhaustion. There was also an effect of role conflict on presenteeism mediated by exhaustion $(\beta=0.08, p<0.01)$. Hypothesis 3 was supported. We examined the indirect effects based on bootstrapped confidence intervals to test the mediation hypotheses. The indirect effects were confirmed at the $95 \%$ level of significance.

There was a negative correlation between presenteeism and work pace $(r=-0.25, p<0.01)$, presenteeism and social support from leader $(r=-0.14, p<0.01)$, and presenteeism and social support from colleagues $(r=-0.14$, $p<0.01$ ). In the SEM analysis where we controlled for job resources there was no direct association between the job resources and presenteeism (see Figure 1). In addition, control over work pace had a negative indirect effect on presenteeism; however, this was not hypothesized $(\beta=-0.08, p<0.01)$. Hypothesis 4 that job resources were negatively related to presenteeism was partly confirmed.

The health impairment process of presenteeism was confirmed, and the hypothesized model had a good fit to the data $\left(\chi^{2}(116)=231.23, p<0.001, \mathrm{GFI}=0.956, \mathrm{CFI}=0.964, \mathrm{SRMR}=0.043\right.$, TLI $=0.953$, and RMSEA $=$ 0.043). The results confirmed direct effects between exhaustion and presenteeism. In addition to mediating effects of variables in the model (Figure 1), the explained variance of presenteeism was 17\% (Table 2).

\section{Discussion}

The results of this study confirmed a positive relationship between presenteeism and exhaustion, and that exhaustion mediates the relationship between job demands and presenteeism. The results support the occurrence of a health impairment process and contribute to the existing literature by simultaneously looking at different kinds of job demands in relation to presenteeism and how this relationship is mediated by exhaustion. We found that job demands can have an indirect association with presenteeism. This indicates that a mere focus on a reduction of either job demands or exhaustion can be inadequate in the reduction of presenteeism. It is important to focus on both factors simultaneously to reduce presenteeism [9] [21] [40]. The study also highlights the importance of the JD-R model as a framework of occupational stress for understanding the process of presenteeism.

The JD-R model suggests that job demands make people exhausted and burned out, and that it is important to gain resources in demanding jobs [17] [18]. The findings of this study confirm the relation between job demands and exhaustion, and contribute to the JD-R literature by applying presenteeism as a job performance variable. Although limited by the cross-sectional design, the current results are in concordance with the existing literature that suggests a reciprocal relationship between exhaustion and presenteeism [8] [9] [21]. However, there is a need for more longitudinal studies examining this specific causal relationship.

The current results indicate an indirect effect of work-family conflict on presenteeism. This highlights how relational demands can contribute to presenteeism among professionals. Relational demands such as work-family conflict differ from other demands because they involve people and relationships within professionals' private sphere that can influence presenteeism [11]. The results show that hospital physicians are more likely to attend work when ill while experiencing work-family conflicts and exhaustion. Findings indicate that to prevent presenteeism it is important to reduce relational demands. This is particularly important when workers manifest symptoms of exhaustion. The significance of relational demands highlights the importance of extending the 
scope of correlates of presenteeism beyond the typical psychosocial and structural job demands in future research. The current results also show that exhaustion mediated the relationship between role conflict and presenteeism in that role conflict through high symptoms of exhaustion increased presenteeism. Experiencing conflicting demands can cause attendance pressures which in turn increase symptoms of exhaustion and presenteeism.

Contrary to our hypothesis, the current study found no support for a relationship between job resources and presenteeism. In the literature, the effects of social support on presenteeism are contradictory [38] [41]-[43] and it remains unclear when and what aspects of presenteeism are affected by social support. However, the current study examined the health impairment process of the JD-R model, suggesting that a supportive work context would decrease presenteeism. It could be beneficial to examine a motivational path between job resources and presenteeism [11] as presenteeism has been associated with resources, work engagement, and work joy [52]. An increased understanding of the complexity of presenteeism, and the association between presenteeism and job resources, may be important for preventing long-term ill-health. Future studies should investigate if the motivational path affects presenteeism and health in the long term.

\subsection{Strengths and Limitations}

In contrast to some studies on presenteeism the operational definition of the current study is specific and contextual. The physicians were asked to consider themselves as patients and relate to situations and conditions where they would have recommended a patient to stay home. The measure of presenteeism used in this study was defined as a period of 12 months and may be prone to recall bias. Changing the time frame of the question by asking the participants to provide their responses according to the prevalence of presenteeism at the last 3, 6, 9 and 12 months can prevent recall bias. Some scholars emphasize the development of a more detailed and objective measure of presenteeism in preference to a single item measure [9] [53] [54]. Firstly, as presenteeism is a subjective state that can be undetectable for others, studies of this phenomenon must rely on self-report, as only the individual knows if he or she attend work sickness present [30]. To prevent different definition of presenteeism it is important to define the phenomenon to participants as in the current study. Secondly, a single-item question and self-reports are shown to be a valid measure of presenteeism [55] [56]. The study confirms similar results on prevalence of presenteeism among physicians, which indicates validity of the current results for the current population of physicians [6]-[8].

The strength of the current study is its high response rate. However, the study is cross-sectional. Longitudinal data including self-reports and objective register data are better suited to confirm causal relationships between the variables in the current model. This would also enable a model that can identify a possible reciprocal relationship between exhaustion and presenteeism. In addition, the antecedents of presenteeism can be heterogeneous across occupations and reduce the generalizability of the current findings. However, many work environments are characterized by high and often conflicting demands, role conflicts, responsibilities, and workload. Although this study focuses on physicians in academic medicine, we believe that the findings are relevant for work environments and occupations that share the same characteristics of high demands and high presenteeism.

\subsection{Practical Implications}

Contrary to intentions, organizational efforts to reduce sickness absences can potentially increase attendance pressure and decrease absence legitimacy which in turn increases presenteeism [11] [38]. This can be negative from a health perspective. Therefore, presenteeism needs to be monitored in addition to sickness absenteeism to capture the complete picture of employees' health status. Emphasizing the assumptions of the JD-R theory could aid leaders, managers, and employees in understanding more about the mechanisms of presenteeism and becoming more skilled in assisting employees to make the right balance between work commitment and concern for their own health. Additional mediation studies are needed to learn more about the health impairment process behind presenteeism. Interactions between job demands and job resources may also be prominent in research on presenteeism in both cross-sectional and longitudinal studies. Research on presenteeism should also include the beneficial aspects of presenteeism [11] [57]. In some situations, it is favorable to attend work when sick rather than be absent. However, this depends on how the workplace, the individual, and the organization make attendance possible in the light of health circumstances [36]. These questions need to be addressed in future studies. 


\section{Conclusion}

A significant contribution of this study is its demonstration that the relationship between job demands and presenteeism is mediated by a health variable. The significance of relational demands highlights the importance of extending the scope of correlates of presenteeism beyond the typical job demands in future research. Job demands, exhaustion, and job resources explained $17 \%$ of the variance of presenteeism and supported the importance of looking at work characteristics mediated through exhaustion. The current study tested these assumptions in terms of the health impairment process. However, it is important to explore these relationships through a motivational path that emphasizes that presenteeism can have positive antecedents and effects on health and well-being.

\section{Acknowledgements}

The authors are grateful to the physicians who participated in this study and to the HOUPE Study Research Group. They would also like to thank Professor Per Øystein Saksvik for his review of the manuscript and helpful suggestions.

\section{References}

[1] Arigoni, F., Bovier, P.A. and Sappino, A.P. (2010) Trend of Burnout among Swiss Doctors. Swiss Medical Weekly, 140, w13070. http://dx.doi.org/10.4414/smw.2010.13070

[2] Houkes, I., Winants, Y., Twellaar, M. and Verdonk, P. (2011) Development of Burnout Over Time and the Causal Order of the Three Dimensions of Burnout among Male and Female GPs. A Three-Wave Panel Study. BMC Public Health, 11, 13. http://dx.doi.org/10.1186/1471-2458-11-240

[3] Peterson, U., et al. (2008) Burnout and Physical and Mental Health among Swedish Healthcare Workers. Journal of Advanced Nursing, 62, 84-95. http://dx.doi.org/10.1111/j.1365-2648.2007.04580.x

[4] Prins, J.T., et al. (2010) Burnout and Engagement among Resident Doctors in the Netherlands: A National Study. Medical Education, 44, 236-247. http://dx.doi.org/10.1111/j.1365-2923.2009.03590.x

[5] McKevitt, C., Morgan, M., Dundas, R. and Holland, W.W. (1997) Sickness Absence and 'Working through’ Illness: A Comparison of Two Professional Groups. Journal of Public Health Medicine, 19, 295-300. http://dx.doi.org/10.1093/oxfordjournals.pubmed.a024633

[6] Rosvold, E.O. and Bjertness, E. (2001) Physicians Who Do Not Take Sick Leave: Hazardous Heroes? Scandinavian Journal of Public Health, 29, 71-75. http://dx.doi.org/10.1177/14034948010290010101

[7] Sendèn, M.G., Løvseth, L.T., Schenck-Gustafsson, K. and Fridner, A. (2013) What Makes Physicians Go to Work While Sick: A Comparative Study of Sickness Presenteeism in Four European Countries (HOUPE). Swiss Medical Weekly, 143, 1-6.

[8] Thun, S., Fridner, A., Minucci, D. and Løvseth, L.T. (2014) Sickness Present with Signs of Burnout: The Relationship between Burnout and Sickness Presenteeism among University Hospital Physicians in Four European Countries. Scandinavian Psychologist, 1, e5. http://psykologisk.no/sp/2014/11/e5/

[9] Demerouti, E., Le Blanc, P.M., Bakker, A.B., Schaufeli, W.B. and Hox, J. (2009) Present But Sick: A Three-Wave Study on Job Demands, Presenteeism and Burnout. Career Development International, 14, 50-68. http://dx.doi.org/10.1108/13620430910933574

[10] Lu, L., Cooper, C.L. and Lin, H.Y. (2013) A Cross-Cultural Examination of Presenteeism and Supervisory Support. Career Development International, 18, 440-456. http://dx.doi.org/10.1108/CDI-03-2013-0031

[11] Miraglia, M. and Johns, G. (2015) Going to Work Ill: A Meta-Analysis of the Correlates of Presenteeism and a DualPath Model. Journal of Occupational Health Psychology, No Pagination Specified.

[12] Gustafsson, K. and Marklund, S. (2014) Associations between Health and Combinations of Sickness Presence and Absence. Occupational Medicine, 64, 49-55. http://dx.doi.org/10.1093/occmed/kqt141

[13] Grinyer, A. and Singleton, V. (2000) Sickness Absence as Risk-Taking Behaviour: A Study of Organisational and Cultural Factors in the Public Sector. Health, Risk \& Society, 2, 7-21. http://dx.doi.org/10.1080/136985700111413

[14] Fridner, A. (2004) Career Paths and Career Patterns among Physicians with a Ph.D. Ph.D. Thesis, Uppsala University, Uppsala.

[15] Bakker, A.B. and Demerouti, E. (2014) Job Demands-Resources Theory. In: Chen, P.Y. and Cooper, C.L., Eds., Work and Wellbeing: A complete Reference Guide, John Wiley \& Sons, New York, 1-28. http://dx.doi.org/10.1002/9781118539415.wbwell019 
[16] Bakker, A.B., Demerouti, E. and Sanz-Vergel, A.I. (2014) Burnout and Work Engagement: The JD-R Approach. Annual Review of Organizational Psychology and Organizational Behavior, 1, 389-411. http://dx.doi.org/10.1146/annurev-orgpsych-031413-091235

[17] Demerouti, E., Bakker, A.B., Nachreiner, F. and Schaufeli, W.B. (2001) The Job Demands-Resources Model of Burnout. Journal of Applied Psychology, 86, 499-512. http://dx.doi.org/10.1037/0021-9010.86.3.499

[18] Demerouti, E., Bakker, A.B., de Jonge, J., Janssen, P.P.M. and Schaufeli, W.B. (2001) Burnout and Engagement at Work as a Function of Demands and Control. Scandinavian Journal of Work Environment \& Health, 27, 279-286. http://dx.doi.org/10.5271/sjweh.615

[19] Bakker, A.B. and Demerouti, E. (2007) The Job Demands-Resources Model: State of the Art. Journal of Managerial Psychology, 22, 309-328. http://dx.doi.org/10.1108/02683940710733115

[20] Demerouti, E., Bakker, A.B., Vardakou, I. and Kantas, A. (2003) The Convergent Validity of Two Burnout Instruments. European Journal of Psychological Assessment, 19, 12-23. http://dx.doi.org/10.1027//1015-5759.19.1.12

[21] De Vroome, E.M.M., Smulders, P.G.W. and Houtman, I.L.D. (2010) Longitudinal Study on the Determinants and Consequences of Presenteeism. Gedrag \& Organisatie, 23, 194-212.

[22] Kalliath, T. and Morris, R. (2002) Job Satisfaction among Nurses: A Predictor of Burnout Levels. Journal of Nursing Administration, 32, 648-654. http://dx.doi.org/10.1097/00005110-200212000-00010

[23] Piko, B.F. (2006) Burnout, Role Conflict, Job Satisfaction and Psychosocial Health among Hungarian Health Care Staff: A Questionnaire Survey. International Journal of Nursing Studies, 43, 311-318. http://dx.doi.org/10.1016/j.ijnurstu.2005.05.003

[24] Allen, T.D., Herst, D.E.L., Bruck, C.S. and Sutton, M. (2000) Consequences Associated with Work-to-Family Conflict: A Review and Agenda for Future Research. Journal of Occupational Health Psychology, 5, 278-308. http://dx.doi.org/10.1037/1076-8998.5.2.278

[25] Kahn, R.L., Wolfe, D.M., Quinn, R.P., Snoek, J.D. and Rosenthal, R.A. (1964) Organizational Stress: Studies in Role Conflict and Ambiguity. John Wiley, Oxford.

[26] Van Steenbergen, E.F., Kluwer, E.S. and Karney, B.R. (2014) Work-Family Enrichment, Work-Family Conflict, and Marital Satisfaction: A Dyadic Analysis. Journal of Occupational Health Psychology, 19, 182-194. http://dx.doi.org/10.1037/a0036011

[27] Carlson, D.S., Kacmar, K.M. and Williams, L.J. (2000) Construction and Initial Validation of a Multidimensional Measure of Work-Family Conflict. Journal of Vocational Behavior, 56, 249-276. http://dx.doi.org/10.1006/jvbe.1999.1713

[28] Greenhaus, J.H. and Beutell, N.J. (1985) Sources of Conflict between Work and Family Roles. Academy of Management Review, 10, 76-88.

[29] Innstrand, S.T., Langballe, E.M., Espnes, G.A., Falkum, E. and Aasland, O.G. (2008) Positive and Negative WorkFamily Interaction and Burnout: A Longitudinal Study of Reciprocal Relations. Work \& Stress, 22, 1-15. http://dx.doi.org/10.1080/02678370801975842

[30] Johns, G. (2011) Attendance Dynamics at Work: The Antecedents and Correlates of Presenteeism, Absenteeism, and Productivity Loss. Journal of Occupational Health Psychology, 16, 483-500. http://dx.doi.org/10.1037/a0025153

[31] Dallner, M., et al. (2000) Validation of the General Nordic Questionnaire (QPSNordic) for Psychological and Social Factors at Work. NORD, Copenhagen

[32] Dellve, L., Hadzibajramovic, E. and Ahlborg Jr., G. (2011) Work Attendance among Healthcare Workers: Prevalence, Incentives, and Long-Term Consequences for Health and Performance. Journal of Advanced Nursing, 67, 1918-1929. http://dx.doi.org/10.1111/j.1365-2648.2011.05630.x

[33] Løvseth, L.T., Fridner, A., Jónsdóttir, L.S., Marini, M. and Linaker, O.M. (2013) Associations between Confidentiality Requirements, Support Seeking and Burnout among University Hospital Physicians in Norway, Sweden, Iceland and Italy (the HOUPE Study). Stress and Health, 29, 432-437. http://dx.doi.org/10.1002/smi.2479

[34] Meijman, T.F. and Mulder, G. (1998) Psychological Aspects of Workload. In: Drenth, P.J.D. and Thierry., H., Eds., Handbook of Work and Organizational Psychology, Hove, Psychology Press. 5-33.

[35] Lu, L., Peng, S.-Q., Lin, H.Y. and Cooper, C.L. (2014) Presenteeism and Health over Time among Chinese Employees: The moderating Role of Self-Efficacy. Work \& Stress, 28, 165-178.

[36] Johns, G. (2010) Presenteeism in the Workplace: A Review and Research Agenda. Journal of Organizational Behavior, 31, 519-542. http://dx.doi.org/10.1002/job.630

[37] Viswesvaran, C., Sanchez, J.I. and Fisher, J. (1999) The Role of Social Support in the Process of Work Stress: A Meta-Analysis. Journal of Vocational Behavior, 54, 314-334. http://dx.doi.org/10.1006/jvbe.1998.1661 
[38] Caverley, N., Cunningham, B.J. and MacGregor, J.N. (2007) Sickness Presenteeism, Sickness Absenteeism, and Health Following Restructuring in a Public Service Organization. Journal of Management Studies, 44, 304-319. http://dx.doi.org/10.1111/j.1467-6486.2007.00690.x

[39] Wallace, J.E. and Lemaire, J. (2007) On Physician Well Being-You'll Get by with a Little Help from Your Friends. Social Science \& Medicine, 64, 2565-2577. http://dx.doi.org/10.1016/j.socscimed.2007.03.016

[40] Deery, S., Walsh, J. and Zatzick, C.D. (2014) A Moderated Mediation Analysis of Job Demands, Presenteeism, and Absenteeism. Journal of Occupational and Organizational Psychology, 87, 352-369. http://dx.doi.org/10.1111/joop.12051

[41] Hansen, C.D. and Andersen, J.H. (2008) Going Ill to Work-What Personal Circumstances, Attitudes and Work-Related Factors Are Associated with Sickness Presenteeism? Social Science \& Medicine, 67, 956-964. http://dx.doi.org/10.1016/j.socscimed.2008.05.022

[42] Johansson, G. and Lundberg, I. (2004) Adjustment Latitude and Attendance Requirements as Determinants of Sickness Absence or Attendance. Empirical Tests of the Illness Flexibility Model. Social Science \& Medicine, 58, 1857-1868. http://dx.doi.org/10.1016/S0277-9536(03)00407-6

[43] Jourdain, G. and Vezina, M. (2014) How Psychological Stress in the Workplace Influences Presenteeism Propensity: A test of the Demand-Control-Support Model. European Journal of Work and Organizational Psychology, 23, 483-496. http://dx.doi.org/10.1080/1359432X.2012.754573

[44] Kivimäki, M., et al. (2005) Working While Ill as a Risk Factor for Serious Coronary Events: The Whitehall II study. American Journal of Public Health, 95, 98-102. http://dx.doi.org/10.2105/AJPH.2003.035873

[45] Lindström, K. (2000) User's Guide for the QPS Nordic: General Nordic Questionnaire for Psychological and Social Factors at Work. Copenhagen

[46] Wannström, I., Peterson, U., Asberg, M., Nygren, A. and Gustavsson, P. (2009) Psychometric Properties of Scales in the General Nordic Questionnaire for Psychological and Social Factors at Work (QPS): Confirmatory Factor Analysis and Prediction of Certified Long-term Sickness Absence. Scandinavian Journal of Psychology, 50, 231-244. http://dx.doi.org/10.1111/j.1467-9450.2008.00697.x

[47] Hellesøy, O.H. (1985) Work Environment Statfjord Field. Work Environment, Health and Safety on a North Sea Oil Platform. Universitetsforlaget, Bergen.

[48] Løvseth, L.T. (2011) The Subjective Burden of Confidentiality. Ph.D. Thesis, Faculty of Medicine, Department of Neuroscience, Norwegian University of Science and Technology, Trondheim.

[49] Hu, L. and Bentler, P.M. (1999) Cutoff Criteria for Fit Indexes in Covariance Structure Analysis: Conventional Criteria versus New Alternatives. Structural Equation Modeling: A Multidisciplinary Journal, 6, 1-55. http://dx.doi.org/10.1080/10705519909540118

[50] Tabachnick, B.G. and Fidell, L.S. (2013) Using Multivariate Statistics. Pearson, Boston.

[51] Cortina, J.M. (1993) What Is Coefficient Alpha? An Examination of Theory and Applications. Journal of Applied Psychology, 78, 98-104. http://dx.doi.org/10.1037/0021-9010.78.1.98

[52] Johansen, V., Aronsson, G. and Marklund, S. (2014) Positive and Negative Reasons for Sickness Presenteeism in Norway and Sweden: A Cross-Sectional Survey. BMJ Open, 4, e004123. http://dx.doi.org/10.1136/bmjopen-2013-004123

[53] Baker-McClearn, D., Greasley, K., Dale, J. and Griffith, F. (2010) Absence Management and Presenteeism: The Pressures on Employees to Attend Work and the Impact of Attendance on Performance. Human Resource Management Journal, 20, 311-328. http://dx.doi.org/10.1111/j.1748-8583.2009.00118.x

[54] Johns, G. (2012) Presenteeism: A Short History and a Cautionary Tale. In: Houdmont, J., Stavroula, L. and Sinclair, R.R., Eds., Contemporary Occupational Health Psychology: Global Perspectives on Research and Practice, John Wiley \& Sons, Chichester, 204-220. http://dx.doi.org/10.1002/9781119942849.ch12

[55] DeSalvo, K.B., Bloser, N., Reynolds, K., He, J. and Muntner, P. (2006) Mortality Prediction with a Single General Self-Rated Health Question. Journal of General Internal Medicine, 21, 267-275. http://dx.doi.org/10.1111/j.1525-1497.2005.00291.x

[56] Johns, G. and Miraglia, M. (2015) The Reliability, Validity, and Accuracy of Self-Reported Absenteeism from Work: A Meta-Analysis. Journal of Occupational Health Psychology, 20, 1-14. http://dx.doi.org/10.1037/a0037754

[57] Thun, S., Saksvik, P.Ø., Mehmetoglu, M., Ose, S.O. and Christensen, M. (2013) The Impact of Supervisors’ Attitudes on Organizational Adjustment Norms and Attendance Pressure Norms. Scandinavian Journal of Organizational Psychology, 5, 15-31. http://sjop.no/index.php/sjop/article/view/355/363 